\title{
Single-centre study comparing standard apical dissection with a modified technique to facilitate vesico-urethral anastomosis during laparoscopic radical prostatectomy
}

\begin{abstract}
Xin Gao*, Xiao-Yong Pu*, Jie Si-Tu and Wen-Tao Huang
A modified apical dissection of the prostate to improve the efficiency of vesico-urethral anastomosis (VUA) in laparoscopic radical prostatectomy (LRP) was reported. A total of 42 patients were randomly selected and enrolled in this study. A standard LRP was performed in 21 patients (group 1), whereas a novel, modified apical dissection of the prostate in LRP was performed in another 21 patients (group 2). Surgical data, total operative time, VUA time, extravasation rate, catheterisation time, occurrence of anastomotic strictures, and the early and late continence rates were analysed statistically. No differences in clinical or pathological characteristics were determined between the two groups. The total operative time, VUA time, blood loss and catheterisation time were lower in group 2, which received the novel, modified technique compared with group 1 , which received the standard technique to dissect the apex of the prostate ( $\boldsymbol{P}<0.01$ for each variable). Regarding the extravasation rate and the occurrence of anastomotic strictures, no significant differences were found between the two groups ( $P>0.05$ for each). After catheter removal, a statistically significant difference in the continence rates was present at 3 and 30 days post operation in the two groups $(P<0.01$, respectively). At 90 days post operation, the difference, although still present, was no longer statistically significant $(\boldsymbol{P}>0.05)$. The novel, modified apical dissection of the prostate facilitates the VUA and significantly improves the efficacy of the procedure and early restoration of continence.
\end{abstract}

Asian Journal of Andrology (2011) 13, 494-498; doi:10.1038/aja.2010.110; published online 7 February 2011

Keywords: continence; laparoscopic technique; radical prostatectomy; vesico-urethral anastomosis

\section{INTRODUCTION}

Prostate cancer is the most commonly diagnosed malignancy in men and also the leading cause of cancer-related death in developed countries, ${ }^{1}$ but its incidence is relatively lower in China. ${ }^{2-4}$ According to the 2002 IARC database, the age-standardized incidence of prostate cancer in China was 1.6 per 100000 person-years, with a mortality rate of 1.0 per 100000 person-years. ${ }^{5}$ It is confirmed that the morbidity of prostate cancer has increased in recent years. ${ }^{4}$

Laparoscopic radical prostatectomy (LRP) has been established as a minimally invasive and viable alternative to the open procedure and is routinely performed in some larger centres in China. ${ }^{2-4}$ LRP is a technically challenging and time-consuming operation that requires not only ablative but also reconstructive laparoscopic skills. ${ }^{6-8}$ The surgical technique of radical prostatectomy has undergone many refinements, resulting in reduced blood loss through better control of the dorsal vein complex and preservation of erectile function by sparing the neurovascular bundles. ${ }^{9}$ The most difficult part of LRP is thought to be the vesico-urethral anastomosis (VUA), requiring considerable training and experience and a relatively long operative time, even when performed by a skilled laparoscopic surgeon; thus, it can be a formidable task for an inexperienced surgeon. ${ }^{10-12}$ The morbidity of an insufficient VUA is well known, causing longer catheterisation and hospital times than those for a dry anastomosis and stricture formation from urine extravasation at the anastomotic site. ${ }^{13-15}$ The VUA can be effectively accomplished with either interrupted or running sutures. Most laparoscopic surgeons perform VUA using interrupted sutures, ${ }^{2,16,17}$ although the trend toward continuous, single-knot sutures is increasing. ${ }^{10,18-25}$ In our institute, we used interrupted sutures in the first 104 patients who underwent VUA, ${ }^{2}$ but because of the variable difficulty in performing the procedure, we turned to the running suture technique. We have confirmed that a modified apical dissection of the prostate as described by Steiner ${ }^{26}$ improves early continence in LRP. ${ }^{2}$ In this study, we tested a novel, modified apical dissection of the prostate. This study was a prospective evaluation of whether the novel, modified apical dissection of the prostate could facilitate the VUA in LRP. The end points of the study were to determine whether the novel, modified apical dissection of the prostate technique could decrease the VUA time and affect the other operative characteristics.

\section{MATERIALS AND METHODS}

Patients

From March 2007 to March 2009, after admission, 42 patients scheduled to undergo an LRP were prospectively randomized into two groups of 21 patients each. The procedure was a standard LRP as described by Walsh. ${ }^{27}$ In group 1 , the single-knot running technique 
alone was used. In group 2, the single-knot running technique was used along with a modified technique for simple dissection of the apical prostate. After giving written consent, participants were asked to participate actively in the random assignment. Each was invited by the manager of the centre to choose an envelope from a basket of 10 envelopes, each of which contained a group assignment. After each randomisation, a new envelope was added to the basket. This added envelope was taken sequentially from a set of envelopes prepared in such a way that each set of envelopes contained five for the control arm and five for the intervention arm. ${ }^{2}$

The Human Ethics Review Committee of the Third Affiliated Hospital, Sun Yat-Sen University, approved the study protocol. All operations were performed by a single surgeon (XG). All patients underwent preoperative urine culture, urodynamics, transrectal ultrasound, intravenous pyelography and either CT or MRI. All factors may affect the bladder, such as retention, urgency, frequency, poor bladder compliance and detrusor instability, were excluded. We recorded all patient characteristics, including age at presentation, mean prostate volume, grade, clinical stage and prostate-specific antigen levels. The operative characteristics were also recorded and compared.

\section{Surgery technique}

Preoperatively, patients were extensively informed of the expected advantages and risks involved in the operation. They also signed an informed consent module approved by our institution's Ethics Committee.

The modified apical dissection of the prostate technique is performed with a transperitoneal approach with a V-shaped arrangement of the trocars (12-mm umbilical port, 12-mm paramedian right port, and three 5-mm ports, one paramedian left and two pararectal) as we have previously described. ${ }^{2}$ After the puboprostatic space is developed, the endopelvic fascia of the prostate is bilaterally dissected longitudinally toward the apex and the puboprostatic ligament section. The dorsal vein complex is divided and sutured with 2-0 Vicryl (Figure 1a). When the bladder neck is transected and its posterior wall is opened, the vas deferens and seminal vesicles are dissected carefully to avoid injury to the pelvic plexus, which runs close to their tips (Figure 1b). The Denonvilliers' fascia is exposed and opened, and the posterior plane of the prostate is created and extended to the apex of the prostate. The lateral vascular pedicle of the prostate is then dissected using a harmonic scissors. Before the prostatic apex mobilisation, a $16 \mathrm{~F}$ catheter is inserted through the prostate. To avoid damaging the continence nerves and the dorsal vein, sharp scissors are used to cut the anterior aspect of the urethra close to the apex of the prostate. When the anterior wall of the proximal urethra is incised, the tip of the catheter is pulled up retrogradely to clearly show the posterior wall of the urethra (Figure 1c; this differs from our previous technique) and a forceps is used to retract the Foley catheter anterogradely and superiorly to reveal the posterolateral urethra. The key step is to dissect and preserve the posterior aspect of the urethra close to the tip of the prostate. The longer urethral stumps were preserved. This is advantageous for VUA. Reconstruction of a new bladder neck requires the use of a longitudinal running 3-0 Vicryl suture. The vesico-urethral anastomotic sutures are placed $3-5 \mathrm{~mm}$ from the transected urethral edge to include mucosa, smooth muscle and muscular sphincter. The 5 and 7 o'clock areas should be avoided so as to minimize the risk of injury to the somatic and autonomic innervations of the external urethral sphincter. ${ }^{2}$ The posterolateral aspect of the external urethral sphincter and median fibrous raphe are subsequently transected proximal to the prostate apex under direct vision (this is
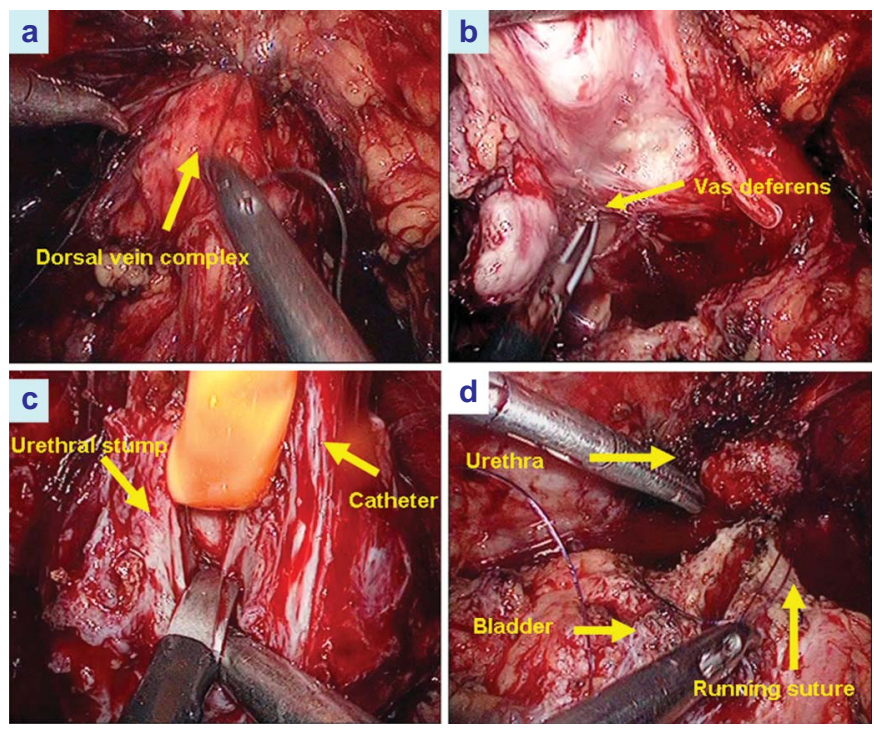

Figure 1 The modified technique for dissection of the apical of the prostate. The dorsal vein complex is divided and sutured (a). The vas deferens and seminal vesicles are dissected carefully to avoid injuring the pelvic plexus (b). Sharp scissors are used to cut the anterior aspect of the urethra close to the apex of the prostate. When the anterior wall of the proximal urethra was incised, the tip of catheter was pulled up retrogradely to clearly show the posterior wall of the urethra. The longer urethral stumps were preserved (c). The VUA was performed using the single-knot running technique (d). VUA, vesico-urethral anastomosis.

done so that the continence nerves can be well preserved before they enter the external urethral sphincter), until the urethra retracts from the posterior prostatic apex and the underlying Denonvilliers' fascia and the rectourethralis muscle are seen. This technique is different from the standard approach in which the rectourethralis muscle and Denonvilliers's fascia are incised after division of the urethra. In our study, for the single-knot running technique in VUA, a 3-0 poliglecaprone suture placed on a 26-mm-long 5/8-circle needle (Monocryl, UR-6; Ethicon, Hamburg, Germany) was used. We performed the VUA using the single-knot running technique as described by van Velthoven et al. ${ }^{21}$ (Figure 1d). During the vesico-urethral suturing, mild tension was put on the posterior margin of the urethra using laparoscopic forceps. To check the quality of the VUA, back-and-forth mobilisation of the catheter was used.

\section{Operative characteristics}

The anastomotic operative time was calculated from the insertion of the first suture through the trocar to the performance of the test of anastomotic tightness using $180 \mathrm{ml}$ of saline solution applied through the urethral catheter at the end of the procedure. Cystography was performed on the fifth or seventh postoperative day, and the catheter was removed in the absence of any extravasation. In the case of severe leakage, the catheter was left in place for another 5 days before checking the anastomosis again with cystography. The strict definition used for the evaluation of urinary continence ${ }^{28}$ was the absence of any diurnal and nocturnal leakage and no pad use.

The groups were compared regarding total operative time, anastomosis time, extravasation rate, catheterisation time, hospital time, occurrence of anastomotic strictures and continence rate at 3, 30 and 90 days from catheter removal. Continence was defined according to Nguyen et al. ${ }^{29}$ Continence was defined as achieving zero pad use or a liner used only for security according to Nguyen et al. ${ }^{29}$ The questions 
concerning continence were asked by a special interviewer in a doubleblind fashion. No patient reported preoperative incontinence.

\section{Statistical analysis}

All data pertinent to outcome assessment were collected. Because the number of cases was small, patients with moderate and severe incontinence were grouped together for purposes of statistical analysis. Categorical variables are summarised in frequency tables, the continuous ones by mean \pm s.d., median and range. For categorical variables, the comparison was performed with the Pearson's $\chi^{2}$-test. For continuous variables either the $t$-test or the Mann-Whitney-Wilcoxon method was used. The level of significance was determined to be $<0.05$. All analyses were performed using the SPSS, version 11.0 (SPSS Inc., Chicago, IL, USA).

\section{RESULTS}

The preoperative data are summarised in Table 1. Patients were similar in terms of follow-up time, age, body mass index, prostate-specific antigen level, prostate volume, Gleason score distribution and stage. No significant differences in these baseline characteristics were found between the two groups ( $P>0.05$, respectively).

For the operative data (Table 2), no difference was observed in transfusion rate, positive margins, positive lymph nodes and hospital time ( $P>0.05$, respectively). Significantly, more blood loss and longer catheterisation time were observed in patients who had undergone a standard LRP (group 1) than in those who had had a modified LRP (group 2, $P=0.01$ for both variables). Of the 42 patients, nine (21.4\%) were deemed appropriate for nerve-sparing procedures. The VUA characteristics for each anastomosis technique are also shown in Table 2. The significant differences between the two groups were the anastomosis operative time and total operative time which were both longer for patients who underwent the standard LRP $(P<0.001$, respectively). The postoperative extravasation rates were similar in the two groups $(P>0.05)$. In two patients $(9.5 \%)$ from group 1 and in three patients (14.3\%) from group 2, slight extravasation was observed on cystography on the fifth postoperative day $(P>0.05)$. Among all these cases, only one patient, from group 2, required

\section{Table 1 Preoperative patient characteristics}

\begin{tabular}{|c|c|c|c|}
\hline Characteristics & $\begin{array}{c}\text { Group } 1 \text { standard } \\
\operatorname{LRP}(\mathrm{n}=21)\end{array}$ & $\begin{array}{c}\text { Group } 2 \text { modified } \\
\operatorname{LRP}(\mathrm{n}=21)\end{array}$ & $\mathrm{P}$ value \\
\hline \multicolumn{4}{|l|}{ Age (year) } \\
\hline Mean \pm s.d. & $64.1 \pm 6.2$ & $64.3 \pm 6.1$ & 0.36 \\
\hline Median (range) & $63(49-78)$ & $64(45-78)$ & \\
\hline PSA (ng ml $\left.{ }^{-1}\right)($ mean \pm s.d. $)$ & $12.2 \pm 6.9$ & $12.7 \pm 7.4$ & 0.68 \\
\hline \multicolumn{4}{|l|}{ Prostate volume $(\mathrm{ml})$} \\
\hline Mean \pm s.d. & $39.8 \pm 5.2$ & $40.2 \pm 3.8$ & 0.64 \\
\hline Median (range) & $42(28-76)$ & $43(26-75)$ & \\
\hline \multicolumn{4}{|l|}{ Clinical stage, $n(\%)$} \\
\hline $\mathrm{T} 1$ & $6(28.6)$ & $7(66.7)$ & 0.64 \\
\hline $\mathrm{T} 2$ & $15(71.1)$ & $14(67.3)$ & \\
\hline \multicolumn{4}{|l|}{ Pathologic stage, $n(\%)$} \\
\hline pT2 & $14(66.7)$ & 13 (61.9) & 0.48 \\
\hline рТЗа & $6(28.6)$ & 7 (33.3) & \\
\hline pT3b & $1(4.7)$ & $1(4.7)$ & \\
\hline \multicolumn{4}{|l|}{ Gleason score, $n(\%)$} \\
\hline$<5$ & $9(42.9)$ & $10(47.6)$ & 0.31 \\
\hline $5-7$ & $9(42.9)$ & 7 (33.3) & \\
\hline$>7$ & $2(9.5)$ & $3(14.3)$ & \\
\hline
\end{tabular}

Abbreviations: LRP, laparoscopic radical prostatectomy; PSA, prostate-specific antigen.
Table 2 Baseline operative and urethrovesical anastomosis characteristics

\begin{tabular}{|c|c|c|c|}
\hline Characteristic & $\begin{array}{l}\text { Group } 1 \text { standard } \\
\qquad \operatorname{LRP}(\mathrm{n}=21)\end{array}$ & $\begin{array}{l}\text { Group } 2 \text { modified } \\
\qquad \operatorname{LRP}(\mathrm{n}=21)\end{array}$ & $\mathrm{P}$ value \\
\hline \multicolumn{4}{|l|}{ Total operative time (min) } \\
\hline Mean \pm s.d. & $187 \pm 68$ & $153 \pm 78$ & \multirow[t]{2}{*}{$<0.001$} \\
\hline Median (range) & $190(150-268)$ & $146(121-237)$ & \\
\hline \multicolumn{4}{|l|}{ Anastomosis time (min) } \\
\hline Mean \pm s.d. & $56 \pm 18$ & $35 \pm 12$ & \multirow[t]{2}{*}{$<0.001$} \\
\hline Median (range) & $57(20-86)$ & $39(11-47)$ & \\
\hline \multicolumn{4}{|l|}{ Blood loss (ml) } \\
\hline Mean \pm s.d. & $120 \pm 98$ & $104 \pm 78$ & \multirow[t]{2}{*}{0.01} \\
\hline Median (range) & $126(150-800)$ & $108(150-900)$ & \\
\hline No. of transfusion (\%) & $2(9.5)$ & $2(9.5)$ & 0.85 \\
\hline $\begin{array}{l}\text { Extravasation on postoperative } \\
\text { cystography, } n(\%)\end{array}$ & $2(9.5)$ & $3(14.3)$ & 0.62 \\
\hline Positive margins, $n(\%)$ & $3(14.3)$ & $3(14.3)$ & 0.95 \\
\hline Positive lymph nodes, $n(\%)$ & $1(4.7)$ & $1(4.7)$ & 0.31 \\
\hline \multicolumn{4}{|l|}{ Hospital time (days) } \\
\hline Mean \pm s.d. & $9.5 \pm 7.7$ & $8.4 \pm 6.7$ & \multirow[t]{2}{*}{0.62} \\
\hline Median (range) & $8(5-14)$ & $8(5-22)$ & \\
\hline \multicolumn{4}{|l|}{ Catheterization time (days) } \\
\hline Mean \pm s.d. & $13.0 \pm 3.8$ & $8.0 \pm 2.8$ & \multirow[t]{2}{*}{0.01} \\
\hline Median (range) & $10(7-15)$ & $10(7-15)$ & \\
\hline $\begin{array}{l}\text { Prolonged drainage }>15 \text { days, } \\
n(\%)\end{array}$ & $0(0)$ & $1(4.7)$ & 0.28 \\
\hline Anastomotic strictures, $n(\%)$ & $0(0)$ & $1(4.7)$ & 0.28 \\
\hline
\end{tabular}

Abbreviation: LRP, laparoscopic radical prostatectomy.

prolonged urinary drainage (for 15 postoperative days). The catheters were removed after a median of 10 days (range 7-15).

Figure 2 indicates the continence rate at 3, 30 and 90 days from catheter removal. Continence recovery was more rapid in the modified LRP group $(P<0.001)$. Even at 3 days after catheter removal, $57.1 \%$ of the patients in group 2 were continent versus $38.1 \%$ of the subjects in group 1. At 30 days, these percentages were $85.7 \%$ and $57.1 \%$, and at 90 days, $95.2 \%$ versus $90.5 \%$, respectively. The difference between the two groups was statistically significant at 3 and 30 days after the procedure ( $P<0.05$ for both). At 90 days, the difference in continence rate between the two groups was no longer statistically significant $(P>0.05)$. During the follow-up period, one patient $(4.7 \%)$ from group 2 developed an anastomotic stricture, which was treated successfully with endoscopic incision.

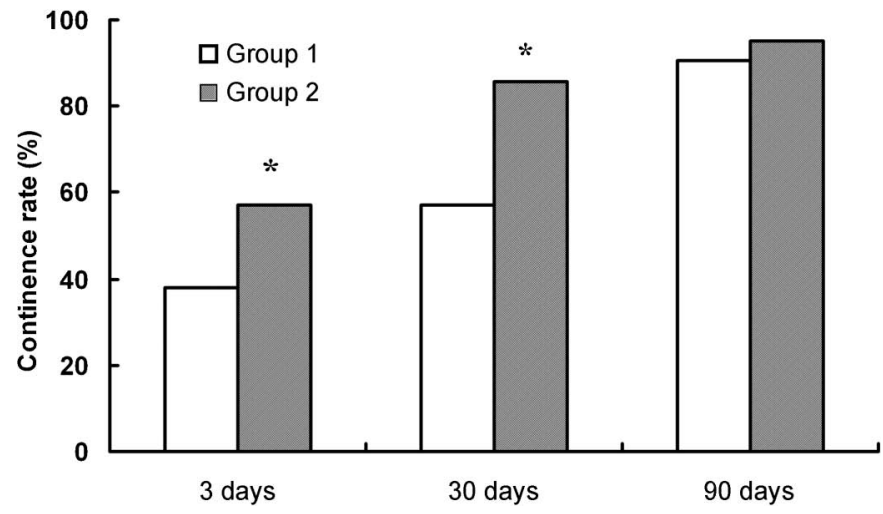

Figure 2 Urinary continence in patients who underwent standard LRP (group 1) and in those who underwent the novel modified LRP (group 2). $* P<0.05$, compared with group 1. LRP, laparoscopic radical prostatectomy. 


\section{DISCUSSION}

LRP, which was developed to reduce surgical complications and hospitalisation time, is emerging as an accepted treatment modality at many worldwide centres. ${ }^{30}$ It has been regarded as a good choice for localised prostate cancer in China. ${ }^{2-4}$ In our previous study, ${ }^{2}$ we conducted a simple apical dissection of the prostate in LRP based on Steiner's technical considerations ${ }^{26,31,32}$ and our previous experience. ${ }^{4}$ In this study, the tip of the catheter was pulled up retrogradely towards the urethra stump to clearly show the posterior wall of the urethra. The key step is to dissect and preserve the posterior aspect of the urethra close to the tip of the prostate. A simple dissection with the cold scissors is sufficient. The longer urethral stumps were preserved, which we did not do in our previous modification; ${ }^{2}$ nor did Steiner. ${ }^{26}$ In our previous modified technique, the catheter was pulled up towards the bladder.

The VUA is the key step in LRP and can be effectively accomplished with either interrupted or running sutures. Based on our previous experience, we performed VUA using running sutures. Poulakis et $a l^{24}$ determined the safety and efficacy of the single-knot running versus interrupted technique for VUA during endoscopic extraperitoneal radical prostatectomy. A total of 250 consecutive patients were prospectively divided into two groups of 125 patients, each of whom underwent VUA using either the single-knot running technique or the interrupted suture technique. No significant differences were found between the two groups with respect to blood loss, extravasation rate, catheterisation time and occurrence of anastomotic strictures $(P>0.05$ for all). In our series, the blood loss and the catheterisation time were obviously decreased in the modified LRP (group 2), which may have been a result of our modification of the simple dissection of the apex of the prostate using cold scissors and preservation of a longer urethral stump.

Many experienced surgeons ${ }^{10,18-20,22-25}$ have favoured the running single-knot anastomotic method of van Velthoven et al. ${ }^{21}$ because of its simplicity and shorter operative time. In this series, the obviously shorter total operative time and the anastomosis operative time were confirmed in patients who underwent the modified LRP and singleknot anastomosis technique ( $P<0.01$ for both), which is in keeping with other reports using only the running suture technique. ${ }^{10,18-25}$ Early catheter removal has been reported to increase the risk of acute retention and recatheterisation. ${ }^{33,34}$ We performed cystography on the fifth to seventh postoperative day in all patients. Although the extravasation rate in the modified LRP group was higher than in the standard LRP group, no significant differences were found between the two groups (two versus three extravasations, respectively, $P>0.05$ ), which is consistent with the results of Poulakis's study. ${ }^{24}$

It has been reported that the anastomotic stricture rate after LRP is low $(0-2 \%),{ }^{14,15,24,35,36}$ although the anastomotic stricture rate after open radical prostatectomy is significantly higher $(4.8-7 \%)$. In our study, we did not find a statistically significant correlation between stricture formation and the type of VUA $(P>0.05)$. Although the causes appeared to be multifactorial, several risk factors, such as urinary extravasation and intraoperative blood loss, seem to be associated with stricture development. ${ }^{24}$ The very low morbidity of anastomotic stricture may be due to the enhanced aspects of VUA during LRP, including the better view of the operative field and the ability to create a completely watertight anastomosis. ${ }^{24}$

Several modifications of open, laparoscopic and robot-assisted LRP (e.g., meticulous or atraumatic apical dissection, ${ }^{2}$ bladder neck preservation, ${ }^{37,38}$ sparing of puboprostatic ligaments ${ }^{39}$ and seminal vesicles, ${ }^{40}$ the length of membranous urethra ${ }^{41,42}$ and preservation of lateral prostatic fascia ${ }^{43}$ ) have been advocated to improve urinary control. However, there remain areas in which modification is still possible to improve immediate continence. The rate of continent LRP patients at 1 year varies from 50 to $91.7 \%$ according to a recent review by Rassweiler ${ }^{44}$ and from 83 to $100 \%$ according to a review by Trabulsi and Guillonneau. ${ }^{45}$ These authors underline the correlation between postoperative continence and the progressive learning curve of the surgeon. In this series, all the procedures were conducted by a single, experienced surgeon. From our results, early continence was significantly improved at catheter removal in the patients who underwent the novel, modified LRP, with results that were essentially identical to those for the standard LRP group. The difference remained statistically significant at 3 and 30 days post surgery. In our previous study, we observed that using the modified dissection of the apex of the prostate in LRP as described by Steiner ${ }^{26}$ is also a simple and effective technique leading to rapid recovery of continence. ${ }^{2}$ However, that procedure was relatively time consuming because of the intensive dissection of the posterior aspect of the urethra. $^{2}$ In this series, the early, rapid recovery of continence was also obtained in the modified group. However, the operative time was shortened because of preservation of the posterior urethral stump.

Although the initial results have been encouraging, our study has some limitations and biases. Although we used a successively alternating randomisation for patient selection, a double-blind randomised evaluation of the anastomosis techniques would have been optimal. No information pertaining to the impact of postoperative incontinence on patients' quality of life was provided. However, this methodological flaw seems common in the LRP literature. ${ }^{2,46}$ For evaluating urethral stricture after the operation, 90 days is a short period. The small number of cases and the short follow-up period are other limitations. A large number of cases, multiple centres and long-term results are required to further investigate this complication.

In conclusion, the novel, modified simple dissection of the apex of the prostate facilitates VUA and provides a watertight anastomosis with a low risk of urethro-vesical stricture in LRP. It is a simple and effective technique. The average operative time and the VUA time for the novel method were both shorter than for the standard technique.

The modified dissection also allows for a much more rapid recovery of continence after LRP compared with the standard LRP. However, additional studies with longer follow-up and larger patient cohorts are needed to confirm the efficacy of this technique.

\section{AUTHOR CONTRIBUTIONS}

XG and XYP developed the concept, designed the study, analyzed the data and drafted the manuscript. XG, XYP, JST and WTH performed the experiment. JST, WTH and XYP participated in implementation of the experiment, data acquisition and preparation of the final manuscript. XG and XYP obtained funding.

\section{COMPETING FINANCIAL INTERESTS}

The authors declare no competing financial interests.

\section{ACKNOWLEDGMENTS}

This study was supported by the National Natural Science Foundation of China (No. 30973011, No. 30772178 and No. 30801147), the Research Fund for the Doctoral Program of Higher Education of China (No. 20060558032), the Natural Science Foundation of Guangdong Province (No. 7117362), the Program of 5010 of Sun-Yat Sen University, China (No. 2007028) and the Fundamental Research Funds for the Central Universities of China.

1 Devesa SS, Blot WJ, Stone BJ, Miller BA, Tarone RE et al. Recent cancer trends in the united states. J Nat/ Cancer Inst 1995; 87: 175-82. 
2 Gao X, Wang KB, Pu XY, Zhou XF, Qiu JG. Modified apical dissection of the prostate improves early continence in laparoscopic radical prostatectomy: technique and initial results. J Cancer Res Clin Oncol 2010; 136: 511-6.

3 Gao X, Zhou JH, Li LY, Qu JG, Pu XY. Laparoscopic radical prostatectomy: oncological and functional results of 126 patients with a minimum 3-year follow-up at a single Chinese institute. Asian J Androl 2009; 11: 548-56.

4 Pu XY, Wang XH, Wu YL, Wang HP. Comparative study of the impact of 3-versus 8month neoadjuvant hormonal therapy on outcome of laparoscopic radical prostatectomy. J Cancer Res Clin Oncol 2007; 133: 555-62.

5 Gu F. Epidemiological survey of benign prostatic hyperplasia and prostatic cancer in China. Chin Med J (Engl) 2000; 113: 299-302.

6 Guillonneau B, Cathelineau X, Doublet JD, Vallancien G. Laparoscopic radical prostatectomy: the lessons learned. J Endourol 2001; 15: 441-5; discussion 447-8.

7 Poulakis V, Dillenburg W, Moeckel M, de Vries R, Witzsch U et al. Laparoscopic radical prostatectomy: prospective evaluation of the learning curve. Eur Urol2005; 47: 16775.

8 Rassweiler J, Sentker L, Seemann O, Hatzinger M, Rumpelt HJ. Laparoscopic radical prostatectomy with the heilbronn technique: an analysis of the first 180 cases. $J$ Urol 2001; 166: 2101-8.

9 Tiguert R, Rigaud J, Fradet Y. Safety and outcome of early catheter removal after radical retropubic prostatectomy. Urology 2004; 63: 513-7.

10 Menon M, Hemal AK, Tewari A, Shrivastava A, Bhandari A. The technique of apical dissection of the prostate and urethrovesical anastomosis in robotic radical prostatectomy. BJU Int 2004; 93: 715-9.

11 Clayman RV. The heilbronn laparoscopic training program for laparoscopic suturing: concept and validation. J Urol 2005; 174: 1848

12 Teber D, Dekel Y, Frede T, Klein J, Rassweiler J. The heilbronn laparoscopic training program for laparoscopic suturing: concept and validation. J Endourol 2005; 19: 230-8.

13 Igel TC, Barrett DM, Rife CC. Comparison of techniques for vesicourethral anastomosis: simple direct versus modified vest traction sutures. Urology 1988; 31: 474-7.

14 Park R, Martin S, Goldberg JD, Lepor H. Anastomotic strictures following radical prostatectomy: insights into incidence, effectiveness of intervention, effect on continence, and factors predisposing to occurrence. Urology 2001; 57: 742-6.

15 Surya BV, Provet J, Johanson KE, Brown J. Anastomotic strictures following radical prostatectomy: risk factors and management. J Urol 1990; 143: 755-8.

16 Guillonneau B, Vallancien G. Laparoscopic radical prostatectomy: the montsouris technique. J Urol 2000; 163: 1643-9.

17 Stolzenburg JU, Do M, Pfeiffer H, Konig F, Aedtner B et al. The endoscopic extraperitoneal radical prostatectomy (EERPE): technique and initial experience. World J Urol 2002; 20: 48-55.

18 LaFontaine P, Chan D, Partin AW, Gurganus R, Hortopan SC et al. Minilaparotomy radical retropubic prostatectomy: updated technique and results. Semin Urol Oncol 2000; 18: 19-27.

19 Hoznek A, Salomon L, Rabii R, Ben Slama MR, Cicco A et al. Vesicourethral anastomosis during laparoscopic radical prostatectomy: the running suture method. J Endourol 2000; 14: 749-53.

20 Shichiri Y, Kanno T, Oida T, Kanamaru H. Facilitating the technique of laparoscopic running urethrovesical anastomosis using Lapra-ty absorbable suture clips. Int J Urol 2006; 13: 192-4.

21 van Velthoven RF, Ahlering TE, Peltier A, Skarecky DW, Clayman RV. Technique for laparoscopic running urethrovesical anastomosis: the single knot method. Urology 2003; 61: 699-702.

22 Abbou CC, Salomon L, Hoznek A, Antiphon P, Cicco A et al. Laparoscopic radical prostatectomy: preliminary results. Urology 2000; 55: 630-4.

23 Lee DI, Eichel L, Skarecky DW, Ahlering TE. Robotic laparoscopic radical prostatectomy with a single assistant. Urology 2004; 63: 1172-5.

24 Poulakis V, Skriapas K, de Vries R, Dillenburg W, Witzsch U et al. Vesicourethral anastomosis during endoscopic extraperitoneal radical prostatectomy: a prospective comparison between the single-knot running and interrupted technique. Urology 2006; 68: 1284-9.

25 Miki T, Okihara K, Ukimura O, Usijima S, Yoneda $\mathrm{K}$ et al. Running suture for vesicourethral anastomosis in minilaparotomy radical retropubic prostatectomy. Urology 2006; 67: 410-2.

26 Steiner MS. Continence-preserving anatomic radical retropubic prostatectomy. Urology 2000; 55: 427-35.

27 Walsh PC. Anatomic radical retropubic prostatectomy. In: Walsh PC, Retik AB, Stamey TA, editors. Campbell's Urology. Philadelphia: WB Saunders; 1997. pp2565-88.

28 Donovan JL, Peters TJ, Abrams P, Brookes ST, de aa Rosette JJ et al. Scoring the short form icsmalesf questionnaire. International Continence Society. J Urol 2000; 164: 1948-55.

29 Nguyen L, Jhaveri J, Tewari A. Surgical technique to overcome anatomical shortcoming: balancing post-prostatectomy continence outcomes of urethral sphincter lengths on preoperative magnetic resonance imaging. J Urol 2008; 179: 1907-11.

30 Gregori A, Simonato A, Lissiani A, Bozzola A, Galli S et al. Laparoscopic radical prostatectomy: perioperative complications in an initial and consecutive series of 80 cases. Eur Urol 2003; 44: 190-4; discussion 194.

31 Steiner MS. Continence-preserving anatomic radical retropubic prostatectomy: the 'No-touch' technique. Curr Urol Rep 2000; 1: 20-7.

32 Steiner MS. Anatomic basis for the continence-preserving radical retropubic prostatectomy. Semin Urol Oncol 2000; 18: 9-18.

33 Patel R, Fiske J, Lepor $\mathrm{H}$. Tamsulosin reduces the incidence of acute urinary retention following early removal of the urinary catheter after radical retropubic prostatectomy. Urology 2003; 62: 287-91.

34 Guillonneau B, Rozet F, Cathelineau X, Lay F, Barret E et al. Perioperative complications of laparoscopic radical prostatectomy: the montsouris 3-year experience. J Urol 2002; 167: 51-6.

35 Salomon L, Sebe P, De La Taille A, Vordos D, Hoznek A et al. Open versus laparoscopic radical prostatectomy: Part ii. BJU Int 2004; 94: 244-50.

36 Salomon L, Sebe P, De la Taille A, Vordos D, Hoznek A et al. Open versus laparoscopic radical prostatectomy: Part i. BJU Int 2004; 94: 238-43.

37 Deliveliotis C, Protogerou V, Alargof E, Varkarakis J. Radical prostatectomy: bladder neck preservation and puboprostatic ligament sparing-effects on continence and positive margins. Urology 2002; 60: 855-8.

38 Freire MP, Weinberg AC, Lei Y, Soukup JR, Lipsitz SR et al. Anatomic bladder neck preservation during robotic-assisted laparoscopic radical prostatectomy: description of technique and outcomes. Eur Urol 2009; 56: 972-980.

39 Poore RE, McCullough DL, Jarow JP. Puboprostatic ligament sparing improves urinary continence after radical retropubic prostatectomy. Urology 1998; 51: 67-72.

40 John H, Hauri D. Seminal vesicle-sparing radical prostatectomy: a novel concept to restore early urinary continence. Urology 2000; 55: 820-4.

41 Coakley FV, Eberhardt S, Kattan MW, Wei DC, Scardino PT et al. Urinary continence after radical retropubic prostatectomy: relationship with membranous urethral length on preoperative endorectal magnetic resonance imaging. J Urol 2002; 168: 1032-5.

42 Borin JF, Skarecky DW, Narula N, Ahlering TE. Impact of urethral stump length on continence and positive surgical margins in robot-assisted laparoscopic prostatectomy. Urology 2007; 70: 173-7.

43 van der Poel HG, de Blok W, Joshi N, van Muilekom E. Preservation of lateral prostatic fascia is associated with urine continence after robotic-assisted prostatectomy. Eur Urol 2009; 55: 892-900.

44 Rassweiler J, Hruza M, Teber D, Su LM. Laparoscopic and robotic assisted radical prostatectomy — critical analysis of the results. Eur Urol 2006; 49: 612-24.

45 Trabulsi EJ, Guillonneau B. Laparoscopic radical prostatectomy. J Urol 2005; 173: 1072-9.

46 Touijer K, Guillonneau B. Laparoscopic radical prostatectomy: a critical analysis of surgical quality. Eur Urol 2006; 49: 625-32. 